\title{
PENDUGAAN PARAMETER DARI DISTRIBUSI GEOMETRIK DENGAN METODE BAYES
}

\author{
SUMINDANG YUZAN, FERRA YANUAR, DODI DEVIANTO \\ Program Studi S1 Matematika, \\ Fakultas Matematika dan Ilmu Pengetahuan Alam, Universitas Andalas, \\ Kampus UNAND Limau Manis Padang, Indonesia. \\ email : Sumindangy@gmail.com
}

Diterima 14 Oktober 2019 Direvisi 21 Oktober 2019 Dipublikasikan 3 Desember 2019

\begin{abstract}
Abstrak. Pendugaan parameter adalah prosedur yang dilakukan untuk menduga parameter populasi dimana parameter tersebut merupakan sebarang nilai yang menjelaskan ciri dari suatu populasi. Pendugaan paramater terdiri dari pendugaan titik dan pendugaan selang. Pendugaan parameter untuk parameter $\theta$ dari distribusi Geometrik menggunakan metode Bayes dengan distribusi prior yang digunakan adalah distribusi $\operatorname{Beta}(\alpha, \beta)$ sebagai distribusi prior konjugat, distribusi Uniform $(0,1)$ sebagai distribusi prior non-konjugat dan distribusi prior Jeffrey sebagai distribusi prior noninformatif. Metode evaluasi yang digunakan untuk mengevaluasi penduga terbaik adalah berdasarkan nilai varian posterior dan lebar credible interval Bayes yang terkecil. Dalam studi simulasi yang dilakukan menunjukkan bahwa distribusi $\operatorname{Beta}(\alpha, \beta)$ menghasilkan nilai dugaan parameter yang lebih baik dari pada distribusi Uniform dan distribusi prior Jeffrey karena menghasilkan nilai varian posterior dan lebar credible interval Bayes yang terkecil.
\end{abstract}

Kata Kunci: Distribusi Beta, Distribusi Geometrik, Metode Bayes.

\section{Pendahuluan}

Statistika adalah suatu ilmu yang mengkaji aturan prosedur dalam pengumpulan, menyajikan, menganalisa suatu data dan menginterpretasikan hasil olahan dari data tersebut. Dalam mempelajari statistika terdapat meode statistik, metode-metode tersebut dikelompokkan ke dalam dua kelompok besar, yaitu statistika deskriptif dan statistika inferensia. Statistika deskriptif adalah metode-metode yang berkaitan dengan pengumpulan dan penyajian suatu gugus data sehingga memberikan informasi yang berguna, sedangkan statistika inferensia mencakup semua metode yang berhubungan dengan analisis sebagian data untuk kemudian sampai pada peramalan atau penarikan kesimpulan mengenai keseluruhan gugus data induknya. Pada statistika inferensia terdapat pendugaan parameter dan pengujian hipotesis. Pendugaan parameter merupakan prosedur untuk menduga parameter popolasi, dimana parameter tersebut merupakan sebarang nilai yang menjelaskan ciri dari suatu popolasi [4]. Pendugaan parameter dari suatu populasi yaitu dengan melakukan pendugaan titik dan pendugaan selang. Pendugaan titik adalah nilai yang diperoleh 
dari suatu sampel digunakan sebagai penduga dari suatu parameter yang nilainya tidak diketahui. Pendugaan selang adalah selang kepercayaan dari suatu parameter yang tergantung dari penduga titik data sampel tersebut [4]. Di dalam pendugaan parameter, terdapat metode yang dapat digunakan diantaranya yaitu metode Bayes. Metode Bayes adalah metode yang menggabungkan distribusi dari sampel dengan distribusi prior. Distribusi prior adalah distribusi awal dari suatu parameter yang memberikan informasi tentang parameter yang tidak diketahui [1]. Gabungan distribusi prior dan fungsi likelihood diperoleh distribusi posterior yang akan menjadi dasar pendugaan dengan menggunakan metode Bayes [2]. Pendugaan parameter dengan metode Bayes menarik karena memungkinkan untuk menggunakan prior informatif untuk memperbarui informasi terkini mengenai parameter yang menarik [5]. Salah satu artikel yang terkait mengenai distribusi Geometrik yakni karakterisasi distribusi geometri senyawa sebagai jumlah dari distribusi gamma [3].

Pada penelitian ini akan dilakukan pendugaan parameter dengan metode Bayes dari peubah acak $X$ yang berdistribusi Geometrik $(\theta)$ dengan menggunakan beberapa distribusi prior.

\section{Data dan Metode}

Data yang digunakan pada studi adalah data bangkitkan dengan program R. Data bangkitan diasumsikan berdistribusi Geometrik $(\theta)$. Metode pendugaan parameter yang digunakan yaitu metode Bayes. Di dalam metode Bayes, untuk mendapatkan pendugaan titik digunakan distribusi prior dan fungsi likelihood untuk kemudian menghasilkan distribusi posterior. Setelah distribusi posterior diperoleh, akan ditentukan posterior mean, varian posterior, credible interval Bayes dan lebar credible interval Bayes. Di dalam artikel ini, akan ditentukan pendugaan parameter dari distribusi Geometrik dengan menggunakan metode Bayes secara analitik dan studi simulasi dengan distribusi prior konjugat, distribusi prior non-konjugat dan distribusi prior non-informatif.

\section{Hasil dan Pembahasa}

\subsection{Fungsi Likelihood dari Distribusi Geometrik}

Misalkan diketahui $X_{1}, X_{2}, \cdots, X_{n}$ merupakan peubah acak yang ber-distribusi Geometrik dengan parameter $\theta$ dengan $X_{i} \sim G E O(\theta)$ untuk $0<\theta<1$, diperoleh fungsi likelihood adalah

$$
\begin{aligned}
f(\boldsymbol{x} \mid \theta) & =\prod_{i=1}^{n} f\left(x_{i} ; \theta\right) \\
& =\prod_{i=1}^{n}\left(\theta(1-\theta)^{x_{i}-1}\right) \\
& =\theta^{n}(1-\theta)^{\sum_{i=1}^{n} x_{i}-n} .
\end{aligned}
$$

Jadi fungsi likelihood dari distribusi Geometrik dengan parameter $\theta$ adalah $f(\boldsymbol{x} \mid \theta)=$ $\theta^{n}(1-\theta)^{\sum_{i=1}^{n} x_{i}-n}$. 


\subsection{Penduga Titik dengan Metode Bayes}

Metode Bayes merupakan salah satu metode untuk menduga parameter. Di dalam metode Bayes terdapat distribusi prior yang digunakan untuk menduga parameter $\theta$. Untuk mendapatkan pendugaan parameter dari distribusi Geometrik dengan paremeter yang diduga $\theta$, akan ditentukan distribusi posterior dari masing-masing prior sehingga diperoleh posterior mean dan varian posterior yang dimana posterior mean merupakan penduga Bayes dari distribusi yang diduga $\theta$. Distribusi prior yang digunakan yakni distribusi prior konjugat, distribusi prior non-konjugat, dan distribusi prior non-informatif.

\subsubsection{Penduga Titik bagi Parameter $\theta$ dengan Menggunakan Distribusi Prior Konjugat}

Distribusi prior konjugat dari suatu distribusi bisa ditentukan menggunakan sebaran keluarga eksponensial karena memiliki kesamaan bentuk fungsional dengan distribusi dari suatu parameter yang akan diduga.

\section{Distribusi Prior Konjugat pada Distribusi Geometrik}

Karena distribusi $\operatorname{Beta}(\alpha, \beta)$ berada pada interval 0 sampai 1 maka distribusi $\operatorname{Beta}(\alpha, \beta)$ dapat digunakan untuk menduga parameter $\theta$ dari distribusi Geometrik, sehingga distribusi prior konjugat dari distribusi Geometrik adalah distribusi $\operatorname{Beta}(\alpha, \beta)$.

Asumsikan $\theta$ merupakan peubah acak dari distribusi prior $\operatorname{Beta}(\alpha, \beta)$ dengan fungsi kepekatan peluang adalah

$$
f(\theta)=\frac{\Gamma(\alpha+\beta)}{\Gamma(\alpha) \Gamma(\beta)} \theta^{\alpha-1}(1-\theta)^{\beta-1}=\frac{\theta^{\alpha-1}(1-\theta)^{\beta-1}}{B(\alpha, \beta)} \propto \theta^{\alpha-1}(1-\theta)^{\beta-1} .
$$

Jadi distribusi $\operatorname{Beta}(\alpha, \beta)$ merupakan distribusi prior konjugat bagi distribusi Geometrik dengan parameter $\theta$.

\section{Distribusi Posterior dari Distribusi Beta sebagai Distribusi Prior Konjugat}

Misal $X_{1}, X_{2}, \cdots, X_{n}$ merupakan peubah acak yang berdistribusi Geometrik dengan parameter $\theta$ atau $X_{i} \sim G E O(\theta)$. Untuk mendapatkan nilai $\alpha$ dan $\beta$, bentuk fungsi likelihood pada persamaan (3.1) dari distribusi Geometrik $X_{i} \sim G E O(\theta)$ dirubah ke dalam bentuk distribusi $\operatorname{Beta}(\alpha, \beta)$ dengan $0<\theta<1, \alpha>0$ dan $\beta>0$ sebagai berikut:

$$
f(\boldsymbol{x} \mid \theta) \propto \theta^{n+1-1}(1-\theta)^{\sum_{i=1}^{n} x_{i}-n+1-1} .
$$

Pada Persamaan (3.3) diperoleh bahwa $\alpha=n+1$ dan $\beta=\sum_{i=1}^{n} x_{i}-n+1$. 
Distribusi posterior dari distribusi Geometrik dengan distribusi Beta sebagai distribusi prior konjugat dapat dinyatakan sebagai berikut:

$$
\begin{aligned}
f(\theta \mid \boldsymbol{x}) & \propto f(\boldsymbol{x} \mid \theta) f(\theta) \\
& =\left(\theta^{n}(1-\theta)^{\sum_{i=1}^{n} x_{i}-n}\right)\left(\theta^{\alpha-1}(1-\theta)^{\beta-1} 1\right) \\
& =\theta^{\alpha+n-1}(1-\theta)^{\beta+\sum_{i=1}^{n} x_{i}-n-1} .
\end{aligned}
$$

Jadi distribusi posterior yang diperoleh dari Persamaan (3.4) merupakan distribusi $\operatorname{Beta}\left(\alpha^{\prime}, \beta^{\prime}\right)$ dimana $\alpha^{\prime}=\alpha+n$ dan $\beta^{\prime}=\beta+\sum_{i=1}^{n} x_{i}-n$, atau dapat ditulis distribusi posterior bagi $\theta$ adalah $\theta_{1} \mid \boldsymbol{x} \sim \operatorname{Beta}\left(\alpha+n, \beta+\sum_{i=1}^{n} x_{i}-n\right)$ dengan $\alpha=n+1$ dan $\beta=\sum_{i=1}^{n} x_{i}-n+1$.

Posterior mean dan varian posterior untuk parameter $\theta_{1}$ adalah

$$
\begin{aligned}
\widehat{\theta}_{\text {1bayes }} & =E(X)=\frac{\alpha+n}{\alpha+\beta+\sum_{i=1}^{n} x_{i}} . \\
\operatorname{Var}\left(\widehat{\theta}_{\text {1bayes }}\right) & =\frac{(\alpha+n)\left(\beta+\sum_{i=1}^{n} x_{i}-n\right)}{\left(\alpha+\beta+\sum_{i=1}^{n} x_{i}+1\right)\left(\alpha+\beta+\sum_{i=1}^{n} x_{i}\right)^{2}} .
\end{aligned}
$$

\subsubsection{Penduga Titik bagi Parameter $\theta$ dengan Menggunakan Distribusi Prior Non-Konjugat}

Distribusi prior non-konjugat merupakan distribusi yang pemberian priornya pada model tidak mengindahkan pola pembentuk fungsi likelihoodnya.

\section{Distribusi Prior Non-Konjugat pada Distribusi Geometrik}

Karena distribusi prior yang diambil tidak mengindahkan pola pembentuk fungsi likelihoodnya maka distribusi prior non-konjugat yang digunakan untuk menduga paremeter $\theta$ dari distribusi Geometrik adalah distribusi Uniform dengan $\theta \sim U N I F(0,1)$ karena $\theta$ harus berada pada selang 0 sampai 1 , sehingga fungsi kepekatan peluang untuk $\theta$ adalah

$$
f(\theta)=1 \text {, untuk } 0<\theta<1 .
$$

Jadi distribusi Uniform $(0,1)$ merupakan distribusi prior non-konjugat bagi distribusi Geometrik $(\theta)$.

\section{Distribusi Posterior dari Distribusi Uniform sebagai Distribusi Prior Non-Konjugat}

Distribusi posterior dari distribusi Geometrik dengan distribusi Uniform sebagai distribusi prior non-konjugat dapat dinyatakan sebagai berikut:

$$
\begin{aligned}
f(\theta \mid \boldsymbol{x}) & \propto f(\boldsymbol{x} \mid \theta) f(\theta) \\
& =\left(\theta^{n}(1-\theta)^{\sum_{i=1}^{n} x_{i}-n}\right)(1) \\
& =\theta^{n}(1-\theta)^{\sum_{i=1}^{n} x_{i}-n} .
\end{aligned}
$$

Jadi distribusi posterior yang diperoleh dari Persamaan (3.8) merupakan distribusi $\operatorname{Beta}(\alpha, \beta)$ dimana $\alpha=n+1$ dan $\beta=\sum_{i=1}^{n} x_{i}-n+1$, atau dapat ditulis distribusi 
posterior bagi $\theta$ adalah $\theta_{2} \mid \boldsymbol{x} \sim \operatorname{Beta}\left(n+1, \sum_{i=1}^{n} x_{i}-n+1\right)$.

Posterior mean dan varian posterior untuk parameter $\theta_{2}$ adalah

$$
\begin{aligned}
\widehat{\theta}_{\text {2bayes }} & =E(X)=\frac{n+1}{\sum_{i=1}^{n} x_{i}+2} . \\
\operatorname{Var}\left(\widehat{\theta}_{2 \text { bayes }}\right) & =\frac{(n+1)\left(\sum_{i=1}^{n} x_{i}-n+1\right)}{\left(\sum_{i=1}^{n} x_{i}+3\right)\left(\sum_{i=1}^{n} x_{i}+2\right)^{2}} .
\end{aligned}
$$

\subsubsection{Penduga Titik bagi Parameter $\theta$ dengan Menggunakan Distribusi Prior Non-Informatif}

Misalkan $X$ peubah acak dengan $X \sim G E O(\theta)$. Salah satu bentuk pendekatan dari distribusi prior non-informatif adalah metode Jeffrey.

\section{Distribusi Prior Non-Informatif pada Distribusi Geometrik} berikut:

Berdasarkan metode Jeffrey, distribusi prior non-informatif diperoleh sebagai

$$
f(\theta) \propto \frac{1}{(1-\theta)^{1 / 2} \theta}
$$

Jadi distribusi prior non-informatif bagi $\theta$ pada distribusi Geometrik adalah $f(\theta) \propto$ $\frac{1}{(1-\theta)^{1 / 2} \theta}$.

\section{Distribusi Posterior dari Metode Jeffrey sebagai Distribusi Prior Non-Informatif}

Distribusi posterior dari distribusi prior Jeffrey dapat dinyatakan sebagai berikut:

$$
\begin{aligned}
f(\theta \mid \boldsymbol{x}) & \propto f(\boldsymbol{x} \mid \theta) f(\theta) \\
& =\left(\theta^{n}(1-\theta)^{\sum_{i=1}^{n} x_{i}-n}\right)\left(\frac{1}{(1-\theta)^{1 / 2} \theta}\right) \\
& =\theta^{n-1}(1-\theta)^{\sum_{i=1}^{n} x_{i}-n-1 / 2+1-1} .
\end{aligned}
$$

Jadi distribusi posterior yang diperoleh dari Persamaan (3.12) merupakan distribusi $\operatorname{Beta}(\alpha, \beta)$ dimana $\alpha=n$ dan $\beta=\sum_{i=1}^{n} x_{i}-n-1 / 2+1$, atau dapat ditulis distribusi posterior bagi $\theta$ adalah $\theta_{3} \mid \boldsymbol{x} \sim \operatorname{Beta}\left(n, \sum_{i=1}^{n} x_{i}-n+1 / 2\right)$.

Posterior mean dan varian posterior untuk parameter $\theta_{3}$ adalah

$$
\begin{aligned}
\widehat{\theta}_{3 \text { bayes }} & =E(X)=\frac{n}{\sum_{i=1}^{n} x_{i}+1 / 2} . \\
\operatorname{Var}\left(\widehat{\theta}_{3 \text { bayes }}\right) & =\frac{(n)\left(\sum_{i=1}^{n} x_{i}-n+1 / 2\right)}{\left(\sum_{i=1}^{n} x_{i}+3 / 2\right)\left(\sum_{i=1}^{n} x_{i}+1 / 2\right)^{2}} .
\end{aligned}
$$

Hasil yang diperoleh dari posterior mean dan varian posterior dari masingmasing distribusi prior dapat dilihat pada tabel berikut: 
Tabel 1. Hasil Perhitungan Pendugaan Titik dan Pendugaan Selang untuk Parameter $\theta$

\begin{tabular}{|c|c|c|}
\hline Distribusi Prior & Posterior Mean & Posterior Variansi \\
\hline Beta & $\frac{\alpha+n}{\alpha+\beta+\sum_{i=1}^{n} x_{i}}$ & $\frac{(\alpha+n)\left(\beta+\sum_{i=1}^{n} x_{i}-n\right)}{\left(\alpha+\beta+\sum_{i=1}^{n} x_{i}+1\right)\left(\alpha+\beta+\sum_{i=1}^{n} x_{i}\right)^{2}}$ \\
\hline Uniform & $\frac{n+1}{\sum_{i=1}^{n} x_{i}+2}$ & $\frac{(n+1)\left(\sum_{i=1}^{n} x_{i}-n+1\right)}{\left(\sum_{i=1}^{n} x_{i}+3\right)\left(\sum_{i=1}^{n} x_{i}+2\right)^{2}}$ \\
\hline Jeffrey & $\frac{n}{\sum_{i=1}^{n} x_{i}+1 / 2}$ & $\frac{(n)\left(\sum_{i=1}^{n} x_{i}-n+1 / 2\right)}{\left(\sum_{i=1}^{n} x_{i}+3 / 2\right)\left(\sum_{i=1}^{n} x_{i}+1 / 2\right)^{2}}$ \\
\hline
\end{tabular}

\subsection{Penduga Selang dengan Menggunakan Credible Interval Bayes}

$\widehat{\theta}_{\text {bayes }}$ merupakan mean atau penduga Bayes bagi penduga $\theta$ dan simpangan baku $\operatorname{Var}\left(\widehat{\theta}_{\text {bayes }}\right)$ merupakan varian dari penduga Bayes. Karena $\sqrt{\operatorname{Var}\left(\widehat{\theta}_{\text {bayes }}\right)}=\sigma_{\text {bayes }}$ merupakan simpangan baku dari penduga Bayes, sehingga selang ke-percayaan (1a) $100 \%$ untuk $\theta$ adalah

$$
\widehat{\theta}_{\text {bayes }}-z_{\alpha / 2} \sigma_{\text {bayes }}<\theta<\widehat{\theta}_{\text {bayes }}+z_{\alpha / 2} \sigma_{\text {bayes }} .
$$

Jadi penduga selang dengan menggunakan credible interval Bayes adalah $\widehat{\theta}_{\text {bayes }}-$ $z_{\alpha / 2} \sigma_{\text {bayes }}<\theta<\widehat{\theta}_{\text {bayes }}+z_{\alpha / 2} \sigma_{\text {bayes }}$.

\subsection{Studi Simulasi}

Data bangkitan yang berdistribusi Geometrik dengan $X_{i} \sim G E O(\theta)$ di-peroleh pada program $\mathrm{R}$ sebanyak 150 buah data yaitu: $15,102,65,5,7,147,38,48,2,30$, $51,60,71,0,26,53,2,62,52,27,0,14,49,65,41,25,41,20,1,109,57,114,85$, $33,92,137,2,24,7,63,174,12,155,12,10,21,26,67,76,26,8,36,31,119,37$, 8, 24, 106, 73, 52, 22, 2, $126170,34,4,2,159,18,12,15,34,137,1,79,69,55$, $12,68,22,63,135,59,142,109,4,21,18,5,25,8,56,130,70,64,26,52,34,43$, $32,55,2,88,54,13,15,19,29,109,102,54,18,55,30,5,109,28,112,39,102$, $39,0,85,40,49,26,95,4,84,46,114,14,54,11,47,79,13,12,137,38,1,10,33$, $29,3,35,57,14,120,100$ dengan menetapkan nilai $\theta=0,02$. Dari data diperoleh $\sum_{i=1}^{n} x_{i}=\sum_{i=1}^{150} x_{i}=7479$. Selanjutnya dilakukan pendugaan titik dan pendugaan selang untuk parameter $\theta$ dari data tersebut dengan menggunakan metode Bayes pada masing-masing distribusi prior.

Hasil perhitungan mean posterior, varian posterior, credible interval Bayes dan lebar credible interval Bayes dari masing-masing distribusi prior yang telah diperoleh dengan menggunakan rumus pada Tabel (1) sebagai berikut: 
Tabel 2. Hasil Perhitungan Pendugaan Titik untuk Parameter $\theta$ dari distribusi Geometrik

\begin{tabular}{|c|c|c|c|}
\hline Peluang $(\theta)$ & Distribusi Prior & Posterior Mean & Varian Posterior \\
\hline \multirow{2}{*}{0,02} & Beta & 0,02012032 & 0,000001317792 \\
& Uniform & 0,02018447 & 0,000002643284 \\
& Jeffrey & 0,02005482 & 0,00000262718 \\
\hline \multirow{2}{*}{0,2} & Beta & 0,2093185 & 0,0001150134 \\
& Uniform & 0,2097222 & 0,0002298735 \\
& Jeffrey & 0,2087683 & 0,0002295818 \\
\hline \multirow{2}{*}{0,3} & Beta & 0,3626506 & 0,000278141 \\
& Uniform & 0,3629808 & 0,0005544982 \\
& Jeffrey & 0,3618818 & 0,0005557722 \\
\hline \multirow{2}{*}{0,4} & Beta & 0,4808307 & 0,000398138 \\
& Uniform & 0,4808917 & 0,0007924917 \\
& Jeffrey & 0,48 & 0,0007961722 \\
\hline \multirow{2}{*}{0,5} & Beta & 0,07838542 & 0,0004400696 \\
& Uniform & 0,07823834 & 0,0008776268 \\
& Jeffrey & 0,07832898 & 0,000881802 \\
\hline \multirow{2}{*}{0,6} & Beta & 1,09058 & $-0,0003566224$ \\
& Uniform & 1,086331 & $-0,0006698855$ \\
& Jeffrey & 1,090909 & $-0,0007160545$ \\
\hline
\end{tabular}

Berdasarkan hasil pendugaan titik pada Tabel (2) di atas diketahui bahwa dengan $\mathrm{n}=150$, distribusi prior Beta untuk $\theta=0,02$ dan $\theta=0,2$ nilai posterior mean yang dihasilkan hampir mendekati nilai yang ditetapkan, untuk $\theta=0,3$ dan $\theta=0,4$ nilai posterior mean yang dihasilkan cukup dekat dengan nilai yang ditetapkan, sedangkan untuk $\theta=0,5$ nilai posterior mean jauh dari nilai yang ditetapkan dan untuk $\theta=0,6$ posterior mean sangat jauh dari nilai yang ditetapkan. Hasil yang sama juga diperoleh untuk distribusi prior Uniform dan distribusi prior Jeffrey. Serta diketahui bahwa varian posterior pada distribusi prior Beta menghasilkan nilai yang lebih kecil dibandingkan distribusi prior Uniform dan distribusi prior Jeffrey. Varian posterior untuk $\theta=0,6$ menghasilkan nilai yang negatif karena nilai posterior mean yang dihasilkan jauh dari nilai yang ditetapkan.

Tabel 3. Hasil Perhitungan Pendugaan Selang untuk Parameter $\theta$ dari distribusi Geometrik

\begin{tabular}{|c|c|c|c|}
\hline Peluang $(\theta)$ & Distribusi Prior & Credible Interval Bayes & Lebar Credible Interval Bayes \\
\hline \multirow{3}{*}{0,02} & Beta & $0,01787034<\theta<0,0223703$ & 0,00449997 \\
& Uniform & $0,01699786<\theta<0,02337117$ & 0,006373207 \\
& Jeffrey & $0,01687794<\theta<0,0232317$ & 0,006353763 \\
\hline \multirow{3}{*}{0,2} & Beta & $0,1882986<\theta<0,2303384$ & 0,04203976 \\
& Uniform & $0,1800055<\theta<0,239438$ & 0,0594334 \\
& Jeffrey & $0,1790704<\theta<0,2384661$ & 0,05939567 \\
\hline \multirow{3}{*}{0,3} & Beta & $0,3299626<\theta<0,3953386$ & 0,06537603 \\
& Uniform & $0,3168271<\theta<0,4091344$ & 0,09230732 \\
& Jeffrey & $0,3156751<\theta<0,4080884$ & 0,0924133 \\
\hline \multirow{3}{*}{0,4} & Beta & $0,441722<\theta<0,5199393$ & 0,07821731 \\
& Uniform & $0,4257153<\theta<0,5360681$ & 0,1103528 \\
& Jeffrey & $0,4246956<\theta<0,5353044$ & 0,1106088 \\
\hline \multirow{2}{*}{0,5} & Beta & $0,7427376<\theta<0,8249707$ & 0,08223312 \\
& Uniform & $0,7243189<\theta<0,840448$ & 0,1161291 \\
& Jeffrey & $0,7250873<\theta<0,8414923$ & 0,116405 \\
\hline \multirow{2}{*}{0,6} & Beta & - & - \\
& Uniform & - & - \\
\hline
\end{tabular}


Berdasarkan hasil pendugaan selang pada Tabel (3) di atas dapat dilihat bahwa untuk ukuran sampel yang sama dengan $\theta=0,02, \theta=0,2, \theta=0,3, \theta=0,4$ dan $\theta=0,5$, credible interval Bayes dari distribusi prior Beta lebih kecil dibandingkan dengan credible interval Bayes dari distribusi Uniform dan distribusi prior Jeffrey. Sedangkan pada $\theta=0,6$ credible interval Bayes dan lebar credible interval Bayes dari distribusi Geometrik tidak bisa didapatkan, karena varian posterior yang dihasilkan bernilai negatif maka simpangan baku tidak bisa didapatkan untuk penduga selang Bayes dari distribusi Geometrik $(\theta)$.

\section{Kesimpulan}

Pada artikel ini telah diuraikan penggunaan berbagai distribusi prior untuk menduga parameter $\theta$ dari data yang berdistribusi Geometrik dengan metode Bayes. Penelitian yang dilakukan secara analitik dan studi simulasi dengan membangkitkan data sebanyak 150 buah data sampel. Hasil secara analitik dan studi simulasi membuktikan bahwa untuk $0<\theta \leqslant 0,4$ nilai posterior mean yang dihasilkan dari distribusi prior Beta cukup dekat dengan nilai yang ditetapkan dibandingan distribusi prior Uniform dan distribusi prior Jeffrey. Untuk $0,4<\theta \leqslant 0,5$ nilai posterior mean yang dihasilkan jauh dengan nilai yang ditetapkan, sedangkan $0,5<\theta \leqslant 1$ nilai posterior mean yang dihasilkan sangat jauh dengan nilai yang ditetapkan. Serta membuktikan bahwa untuk $0<\theta \leqslant 0,5$ nilai varian posterior dan lebar credible interval Bayes pada distribusi prior Beta menghasilkan nilai yang lebih kecil di-bandingkan distribusi prior Uniform dan distribusi prior Jeffrey. Untuk $0,5<\theta<1$ nilai varian posterior menghasilkan nilai yang negatif karena nilai posterior mean yang dihasilkan jauh dari nilai yang ditetapkan, dan nilai credible interval Bayes tidak bisa didapatkan karena nilai varian posterior bernilai negatif. Dapat disim-pulkan bahwa distribusi Beta sebagai distribusi prior konjugat menghasilkan nilai dugaan parameter yang lebih baik, karena menghasilkan nilai varian posterior dan lebar credible interval Bayes yang terkecil, jika dibandingkan dengan distibusi uniform sebagai distribusi prior non-konjugat dan distribusi prior jeffrey sebagai distribusi prior non-informatif.

\section{Daftar Pustaka}

[1] Box, G.E.P. and G.C. Tiao. 1973. Bayesian Inference in Statistical Analysis. Second Edition. Addison-Weshley Publishing Company, London.

[2] Casella, G and R.L. Berger. 2001. Statistical Inference. Second Edition. Pacific Grove, California.

[3] Devianto, D., Maiyastri, Putri, D.M. 2018. The Definite Positive Property of Characteristic Function from Compound Geometric Distribution as The Sum of Gamma Distribution. Journal of Science and Technology 3(1): 49 - 52.

[4] Walpole, R.E and R.H. Myers. 1995. Probability and Statistics for Engineers Scientists. Eighth Edition. Pearson Education Inc, New of America.

[5] Yanuar, F., Ibrahim, K., and Jemain, A.A. 2013. Bayesian Structural Equation Modeling for the Healt Index. Journal of Applied Statistics, 40(6): $1254-1269$. 